\title{
A CASE OF HYPOCALCEMIA-INDUCED DILATED CARDIOMYOPATHY
}

\author{
JOONG KYUNG SUNG, MD, JANG-YOUNG KIM, MD, PHD, DONG-WOOK RYU, MD, JUN-WON LEE, MD, \\ YOUNG-JIN YOUN, MD, BYUNG-SU YOO, MD, PHD AND KYUNG-HOON CHOE, MD, PHD \\ DIVISION OF CARDIOLOGY, DEPARTMENT OF INTERNAL MEDICINE, WONJU COLLEGE OF MEDICINE, YONSEI UNIVERSITY, \\ WONJU, KOREA
}

Hypocalcemia is a rare cause of dilated cardiomyopathy. Hypocalcemia induced cardiomyopathy is usually reversible when calcium level returns to normal range. We experienced a case of 57-year-old woman who had suffered from hypocalcemia after total thyroidectomy and its consequence of dilated cardiomyopathy. After supplementation of calcium and vitamin D, symptoms of heart failure and LV function were recovered.

KEY WORDS: Hypocalcemia · Dilated cardiomyopathy.

\section{INTRODUCTION}

Calcium plays an important role in myocardial contractility. Severe extracellular hypocalcemia impair cardiac contractility because the sarcoplasmic reticulum is unable to maintain sufficient amount of calcium content to initiate myocardial contraction. ${ }^{1)}$ Hypocalcemia is a rare reversible cause of dilated cardiomyopathy (DCMP), and there is no published case in Korea. ${ }^{2}$ We here described a case of DCMP that caused by hypocalcemia after total thyroidectomy and recovered completely after supplementation of oral calcium and vitamin D.

\section{CASE}

A 57-year-old female was admitted to our hospital due to dyspnea (NYHA class III) and generalized edema for 3 days. She also complained of the numbness on both hands and feet for 2 months. She had a history of total thyroidectomy 6 month ago due to thyroid storm which was caused by subacute granulomatous thyroiditis. She had taken synthyroid as a daily medication after thyroidectomy. She had no history of hypertension, diabetes mellitus or smoking. On physical examination, blood pressure was $106 / 74 \mathrm{mmHg}$, heart rate was $75 / \mathrm{min}$, and body temperature was $37^{\circ} \mathrm{C}$. On auscultation of chest, there were coarse breathing sounds with rale and wheezing on both lung fields, and S3 gallop and grade III systolic murmur on apex were heard. Chest radiograph showed mild cardiomegaly with increased pulmonary vascularity on both lung field (Fig. 1A). Her electrocardiogram (ECG) showed normal sinus rhythm with $\mathrm{T}$ wave inversion in the anterolateral leads. Laboratory studies revealed C-reactive protein of $0.85 \mathrm{mg} / \mathrm{dL}$ (reference range; $<1.0 \mathrm{mg} / \mathrm{dL}$ ), magnesium of $1.5 \mathrm{mg} / \mathrm{dL}$ (reference range; $1.6-3.0 \mathrm{mg} / \mathrm{dL}$ ), albumin of $3.8 \mathrm{~g} / \mathrm{dL}$ (reference range; $2.8-5.7 \mathrm{mg} / \mathrm{dL}$ ), corrected calcium of $5.16 \mathrm{mg} / \mathrm{dL}$ (reference range; 8.6-10 $\mathrm{mg} / \mathrm{dL}$ ), and ionized calcium of $0.44 \mathrm{mmol} / \mathrm{L}$ (1.13-1.32). $\mathrm{CK}-\mathrm{MB}$ and troponin-I were in normal range, whereas brain natriuretic peptide (BNP) was $417.6 \mathrm{pg} / \mathrm{mL}$ (reference range; $£^{\circ} 100 \mathrm{pg} / \mathrm{mL}$ ). In the hormone analysis, free T4 and thyroid stimulating hormone (TSH) were in normal range, however intact parathyroid hormone (PTH-I) was 12.45 $\mathrm{pg} / \mathrm{mL}$ (reference range; $15-65 \mathrm{pg} / \mathrm{mL}$ ). Vitamin D level was in normal range.

The transthoracic echocardiography showed global hypokinesia of the LV with $37 \%$ of left ventricular ejection fraction (EF). The left ventricular (LV) end-diastolic dimension was $6.8 \mathrm{~cm}$ (Fig. 2A). Mitral regurgitation was observed due to incomplete coaptation of both leaflets. The effective regurgitant orifice (ERO) was $0.33 \mathrm{~cm}^{2}$ and mitral regurgi- 

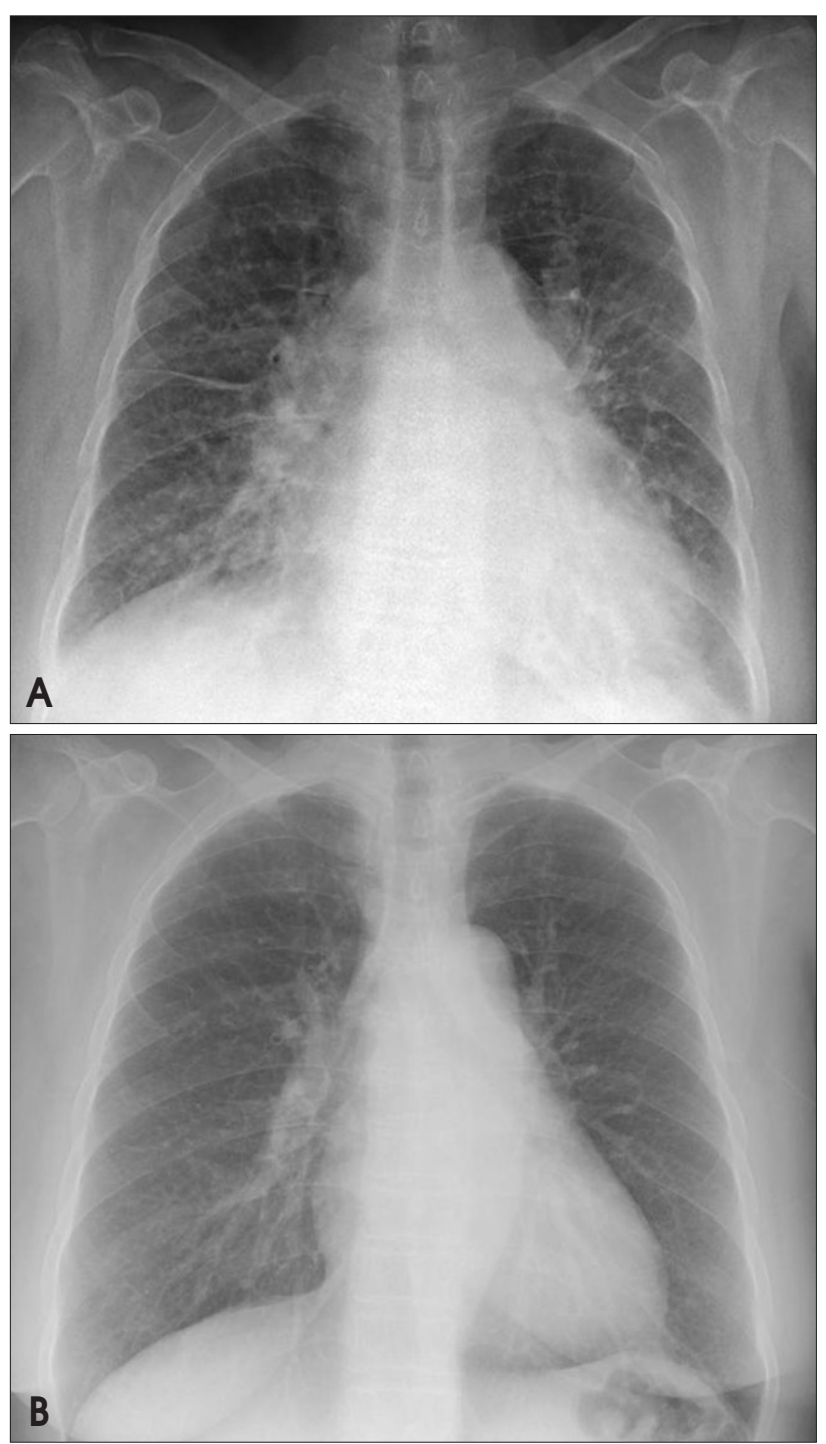

Fig. 1. Chest radiography on admission revealed cardiomegaly and increased pulmonary vascularity in both lung filed (A). Cardiomegaly and pulmonary congestion improved on follow up at 5 months after medical treatment (B).

tation volume was $40 \mathrm{cc}$ in the calculation of proximal isovelocity surface area (PISA) method. The mitral inflow diastolic pattern showed restrictive physiology (Fig. 2B). The $\mathrm{E} / \mathrm{E}^{\prime}$ was calculated as 31 . There were no significant stenotic lesions on both coronary arteries in coronary arteriogram. We diagnosed as a DCMP due to severe hypocalcemia. We prescribed the oral calcium, vitamin D3, furosemide and candesartan.

Five months after these medications, corrected calcium level was increased from $5.16 \mathrm{mg} / \mathrm{dL}$ to $9.3 \mathrm{mg} / \mathrm{dL}$. She is free of symptoms such as dyspnea, generalized edema and numbness of extremities. Chest radiograph showed no cardiomegaly and pulmonary congestion (Fig. 1B). In the follow up echocardiographic evaluation, LV ejection fraction $(37 \%$ to $61 \%)$ and LV end-diastolic dimension $(6.8$ to $5.6 \mathrm{~cm})$ were normalized (Fig. 2C). Mitral regurgitation was disappeared. Transmitral inflow patterns was changed from restrictive pattern (E/A ratio: 2.94) to abnormal relaxation pattern (E/A ratio: 0.69 ) (Fig. 2D), and E/E' ratio was decreased from 31 to 14 .

\section{DISCUSSION}

We present a case of hypocalcemia-induced DCMP which is improved by calcium and vitamin $\mathrm{D}$ replacements. Although hypocalcemia-induced DCMP was previously reported in several papers, it is a rare cause of reversible DCMP after strumectomy. ${ }^{23)}$

Ionized calcium has a central role for regulating myocardial contraction. During the cardiac action potential is activated, ionized calcium enter intracellular through depolarizationactivated calcium channels. Entered ionized calcium triggers calcium release from the sarcoplasmic reticulum (SR). $\mathrm{Ca}^{2+}$ bind to the myofilaments proteins such as troponin $\mathrm{C}$ initiate contraction of myocardium. ${ }^{1)}$ There are two main ways to change contractility of myocardium. One is altering of amplitude or duration of $\mathrm{Ca}^{2+}$ transient, another is altering of sensitivity of the myofilaments to $\mathrm{Ca}^{2+}$. ${ }^{1)}$ Therefore, hypocalcemia induced DCMP is developed by the altering of amplitude or duration of $\mathrm{Ca}^{2+}$ transient.

Parathyroid hormone has been known to stimulate renal calcium ion re-absorption. In the parathyroidectomy rats, sodium and calcium ion exchange activity was decreased by $40 \%$ and this activity was restored by infusion of PTH. ${ }^{4)}$ Reduced urinary excretion of sodium leads water retention and it may cause heart failure. ${ }^{45)}$

Hypocalcemia cause not only heart failure, but also elevating cardiac enzyme and ST segment changes in ECG which mimics with acute myocardial infarction. ${ }^{.}$Walters explained that cell membrane potential is lower in the condition of hypocalcemia, which increase cell membrane permeability and muscle enzyme is leakage from the cells." However, the elevated cardiac enzyme usually return to normal after treatment of hypocalcemia.

Tingling sensation is a typical symptom of hypocalcemia. Severe hypocalcemia or rapid occurrence of hypocalcemia accompany with chvostek and trousseau's sign. However, in this case, the patient did not complain these symptoms, which suggest that hypocalcemia may have gradually occurred over several months.

In our case, serum level of hypocalcemia was corrected within several days after calcium supplement. However, improvement of phenotype, such as restoration of LV systolic function and chamber size, was achieved by far later. Correction of serum level of calcium did not sufficient for restoration of myocardial function. Rather, it is thought that restoration of intracellular calcium level is more important to 

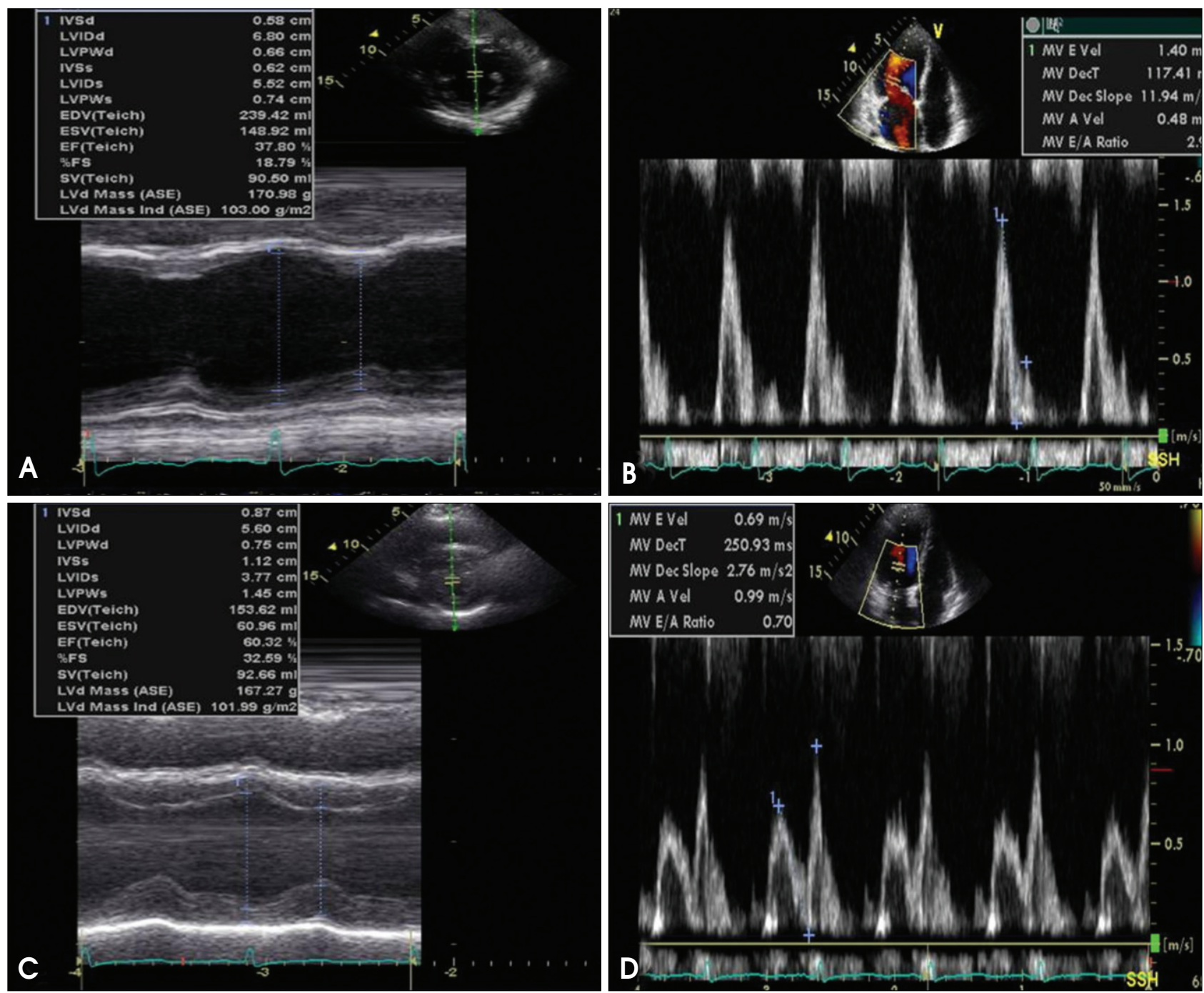

Fig. 2. Transthoracic echocardiography on admission revealed increased left ventricular end diastolic dimension $(6.8 \mathrm{~cm})$ and $37 \%$ of left ventricular ejection fraction (EF) (A). Mitral inflow diastolic pattern showed restrictive physiology with E/A ratio was 2.94 (B). LV ejection fraction and LV enddiastolic dimension was normalized (C), and transmital inflow patterns was improved from restrictive physiology (E/A ratio: 2.94) to abnormal relaxation pattern (E/A ratio: 0.69) (D).

restore myocardial function. It would take a few months to normalized tissue calcium level. ${ }^{8)}$

The echocardiographic and hemodynamic improvement of hypocalcemia-induced DCMP could not be achieved by conventional medical treatments of heart failure. ${ }^{3)}$ In the experience of Gurtoo et al.,") discontinuation of calcium supply leaded reappearance of heart failure. Calcium and vitamin $\mathrm{D}$ treatment is most important in treatment of hypocalcmia induced cardiomyopathy. Furthermore, furosemide may aggravate hypocalcmia by increasing urinary calcium excretion. So, it is necessary to closer monitoring of serum calcium level in the treatment of heart failure patient with severe hypocalcmia.

\section{REFERENCES}

1. Bers DM. Cardiac excitation-contraction coupling. Nature 2002;415:
198-205.

2. Avsar A, Abdullah D, Taveli T. A rare cause of reversible dilated cardiomyopathy: hypocalcemia. Echocardiography 2004;21:609-12.

3. Avramides DA, Ionitsa SS, Panou FK, Ramos AN, Koutmos ST, Zacharoulis AA. Dilated Cardiomyopathy and Hypoparathyroidism: Complete Recovery after Hypocalcemia Correction. Hellenic J Cardiol 2003;44:150-4.

4. Jayakuma A, Cheng L, Liang CT, Sacktor B. Sodium gradientdependent calcium uptake in renal basolateral membrane vesicles. Effect of parathyroid hormone. J Biol Chem 1984;259:10827-33.

5. Giles TD, Iteld J, Rives KL. The cardiomyopathy of hypoparathyroidism. Another reversible form of heart muscle disease. Chest 1981;79:225-9.

6. Pallidis LS, Gregoropoulos PP, Papasteriadis EG. A case of severe hypocalcemia mimicking myocardial infarction. Int J Cardiol 1997;61: 89-91.

7. Walters RO. Idiopathic hypoparathyroidism with extrapyramidal and myopathy features. Arch Dis Child 1979;54:236-8.

8. Breslau NA, Pak CY. Hypoparathyroidism. Metabolism 1979;28:126176.

9. Gurtoo A, Goswami R, Singh B, Rehan S, Meena HS. Hypocalcemiainduced reversible hemodynamic dysfunction. Int J Cardiol 1994;43:91-3. 